\title{
Inventem um Calendário: fabulações produzindo elo entre a vida e a ficção
}

\section{Create a Calendar: confabulations producing link between life and fiction}

\author{
Fernanda de Oliveira Azevedo* \\ Margareth Aparecida Sacramento Rotondo**
}

\begin{abstract}
Resumo
Uma proposição de aula com unidades de medida e dispositivos de organização de tempo. Uma turma do sexto ano de uma escola pública. Certezas abaladas. Desconfianças em composição. Estabelecido em risco de variação. Invenção em processualidade. Junto a uma pesquisa de formação de professoras e professores, uma aula de matemática produz encontros com a Educação e com a Educação Matemática. Como nos constituímos com e em embate com o estabelecido? Como, fugindo com ele, inventamos modos de viver e mundo? Crianças implicadas com o fazer com uma atividade de elaboração de e com calendários produzindo viver. Respirando, submergindo, emergindo, escapando por frestas, arranhando um muro prévio. Fluxos compondo uma aula de matemática. Compondo formação. Inventando escola. Produzindo Educação.
\end{abstract}

Palavras-chave: Invenção. Produção de subjetividade. Produção de mundo. Política cognitiva inventiva.

\begin{abstract}
A class proposition with units of measurement and time organizing devices. A sixth year class of a public school. Assurances shaken. Growing suspicions. Established in a variation risk. Invention in processuality. Along with the training of research teachers and teacher education, a math class produces meetings with Education and Mathematics Education. How do we established ourselves with and clash with the established? How, in getting away with it, we invent ways of living and different worlds? Children involved ino with an activity of preparing and producing calendars. Breathing, submerging, emerging, escaping through cracks, clawing previous walls. Fluxes composing a math class. Writing training. Inventing school. Producing Education.
\end{abstract}

Keywords: Invention. Subjectivity production. World production. Inventive cognitive politics.

\section{Uma aula de matemática e um calendário tornando-se outros ${ }^{* * *}$}

Onde ontem, hoje e amanhã são a mesma coisa Sem a ideia ilusória de que o dia, a noite e a madrugada são coisas distintas. Separadas pelo canto de um galo velho (TEATRO MÁGICO, 2003).

\footnotetext{
* Mestra em Educação pela Universidade Federal de Juiz de Fora (PPGE/UFJF). Professora de Matemática da Educação Básica pela Secretaria de Educação do Estado de Minas Gerais (SEE/MG), Juiz de Fora, Minas Gerais, Brasil. Endereço para correspondência: Rua Barão de Santa Helena, nº 800, Granbery, CEP 36010520, Juiz de Fora, Minas Gerais, Brasil. E-mail: azevedof.oliveira@gmail.com.

** Doutora em Educação Matemática pela Universidade Estadual Paulista (UNESP/Rio Claro). Professora da Faculdade de Educação e do Programa de Pós-graduação da Universidade Federal de Juiz de Fora (UFJF), Juiz de Fora, Minas Gerais, Brasil. Endereço para correspondência: Rua José Lourenço Kelmer, s/n - Martelos, CEP 36036-330, Juiz de Fora, Minas Gerais, Brasil. E-mail: margarethrotondo@ gmail.com.

${ }^{* * * *}$ Este artigo foi apresentado numa versão preliminar no VII Encontro Mineiro de Educação Matemática.
} 
Inventem um calendário. Vocês podem inventar tudo: nomes e quantidades e dias e feriados ${ }^{1}$.

Junto a uma pesquisa de formação ${ }^{2}$ de professoras e professores ${ }^{3}$, uma aula de matemática com uma turma de sexto ano do Ensino Fundamental de uma escola estadual produz encontros com a Educação, com a Educação Matemática, com modos de existir e com produção de mundo. Nessa perspectiva, pergunta-se: há abertura com uma atividade com unidades de medida e um dispositivo de organização de tempo proporcionando invenção? O mínimo de critérios prévios para que se dê o máximo de produção? Algum critério como garantia? Uma decisão, um critério: abertura. Garantia de alguma produção?

Aposta no encontro com um problema num desarranjo do tempo cronológico em uma sala de aula de matemática. Aposta na invenção. Invenção ligada à cognição que guarda uma instabilidade intrínseca e é aí que a invenção opera como "a potência que a cognição tem de diferir de si mesma, de transpor seus próprios limites” (KASTRUP, 1999, p. 55).

Com a aposta, dispara-se um inventar: calendários. Uma decisão aliada a uma política cognitiva inventiva (KASTRUP, 1999): abertura ao inusitado, ao desassossego, à invenção de modos de operar.

\section{Produção de modos de pensar e um grito pela normalidade}

As crianças, envolvidas e concentradas, não afastavam os lápis das folhas de caderno por mais do que alguns instantes. Junto a isso, diziam os nomes e motivos de comemorações rabiscadas em seus calendários. Compartilhavam suas produções. Gargalhavam. Remexiamse. Agitavam-se.

Todo aquele entusiasmo estava à conta de um transbordamento. Produzir um calendário acionava mais que criatividade, aquela que pode ser entendida como "uma função de criação, distribuída, até certo ponto, por todos os seres humanos. [...] uma capacidade comum a todos os indivíduos" (KASTRUP, 1999, p. 15). Produziam-se escapes aos discursos,

\footnotetext{
${ }^{1}$ No decorrer do artigo, serão apresentadas as vozes da professora, das alunas e dos alunos que compõem uma aula de matemática que será o disparador desta escrita. Essas vozes aparecerão em formato do texto, destacandose em itálico.

2 Pesquisa em Educação Básica - acordo CAPES-FAPEMIG, Edital 13/2012, processo APQ-03416-12, coordenado pela professora Dra. Margareth Ap. Sacramento Rotondo.

${ }^{3}$ Durante a pesquisa, muitos atravessamentos se deram no sentido de empoderar modos de vida através de ações como a escrita. Nesse artigo, optamos por demarcar o gênero feminino antecipando o masculino, em inversão ao modo usual, questão exercitada inicialmente com a bolsista de mestrado da pesquisa na produção de sua dissertação.
} 
que compunham sentidos para aula, para matemática, para escola, para aluna e aluno, para professora e professor, sobre tarefa ou disciplina ou disciplina escolar. Discursos instituindose com e na, por exemplo, família, com e na educação escolar e com e no Estado, e com e em tantos outros ou tantas outras.

Produzia-se com papel, lápis e tempo: calendário. Desfazia-se das amarras e dos modos postos. Não consistia em um momento de recreação em que se destituíam do compromisso escolar com a aprendizagem e apropriação de saberes como alunas e alunos. Constituía-se como uma prática que solicitava implicação na invenção de novos modos de operar com o tempo vívido da vida. E implicação prolonga-se aos modos de viver. Não mais criatividade acionada, agora invenção de modos de operar com tempo numa aula de matemática numa escola, numas vidas.

\section{Espera aí! Esses calendários não são normais!}

Assim diziam as pequenas mãos em sinalização de pare! Os braços frenéticos posicionados à frente do tronco lançavam-se em questão com a normalidade assumida. E à frente daquele corpo, uma folha repleta de palavras e riscos tabelados. Um calendário fazia-se no papel sobre a mesa, emergindo com um incômodo incessante gritado do meio da sala.

\section{Espera aí! Esses calendários não são normais!}

Outros corpos lançavam-se junto a uma normalidade assumida natural. Outros mantinham-se no fazer. Do canto abaixo da janela, os olhos vidrados no papel, que também vinha sendo preenchido com a fazeção de outro calendário, acompanhava um dedo indicador em riste, se manifestando:

Normais não! Estes calendários não são iguais ao nosso.

Embrulho na garganta. Normais? Como assim? Normais e iguais ao nosso são expressões equivalentes? Não são? Como assim?

Corpo conformado com a norma, confortável. Corpo: “[...] um meio provedor disputado por uma pluralidade de forças" (DELEUZE, 1976, p. 21), solicitando a presença ativa de uma norma em função da manutenção de um tipo vida. Grito pelo "poder de normalização [...] cuja função maior seria a de repressão, cujo nível de eficácia seria essencialmente superestrutural, da ordem da superestrutura, enfim cujos mecanismos seriam essencialmente ligados ao desconhecimento, à cegueira" (FOUCAULT, 2001, p. 53).

Um modo normativo de vida em embate com uma abertura à desestabilização do instituído. Um embate de forças com a vida, fazendo-se em tempo inventado junto a uma organização do tempo cronológico de vida. Escape a uma norma do cronológico com o 
cronológico, uma abertura intensa à variação. Uma invenção de tempos outros não normais $e$ não iguais, admitindo variação e desestabilização.

Corpos voltavam-se aos traços de dias, de semanas, de tempo outro. Uma contaminação no normatizado cronológico dá-se em vida faceira de uma menina:

Então, nós podemos organizar os dias de outras maneiras, por outras categorias, $e$ podemos ter um mês de dez dias e outro de cinquenta, dependendo do tema do mês.

E, do outro lado da sala, frente o material organizado com traçados de um calendário inventando-se, anuncia-se em postura rígida e em voz de menino perturbado:

Mas, por que um grupo de pessoas usaria um calendário assim?

De pronto, vem de outro lado, sem hesitação:

\section{Porque eles nunca foram à escola!}

Risos emergem e tomam a sala de aula de matemática. Lá, na escola e, também, em casa ensina-se o calendário. Aquele: o certo e o único. Aquele que se deve aprender para orientar o conviver em sociedade, o com-viver em sociedade. Que calendário? O único? Que aprender? Que viver com? Que sociedade?

Mergulhadas e mergulhados em fazeção, os alunos e as alunas seguiam produzindo suas ficções. "Ora, mas a ficção não se opõe ao real? A ficção se opõe ao modelo de verdade. Quer dizer: o que está em jogo não é a veracidade ou não da ficção:” (CLARETO; ROTONDO, 2014, p. 985) o calendário normal é tão verdadeiro quanto qualquer outra ficção. Um calendário posto, reconhecido e naturalizado: uma ficção. Fabulava-se com invenção de calendários.

Encontrar a função fabuladora é reencontrar o elo entre a vida e a ficção. É fazer ver a realidade da ficção, é fazer ver que a sua potência falsificadora é, antes de tudo, uma potência criadora de mundos, de mundos habitáveis e vivíveis. Portanto o que é afirmado não é a verdade da ficção, mas sua realidade falsificadora. Talvez a tenhamos separado da vida por prudência (PIMENTEL, 2010, p. 134).

Uma ficção e sua realidade falsificadora são criadoras de mundos. Fabulam-se calendários e com calendários fabulados naquela sala de aula de matemática. Ficções com criação de tempos outros e modos outros de estar no mundo, inventam realidades outras.

Novas realidades em mundos vivíveis e habitáveis. Vidas outras inventadas. Outros modos de estar em outros mundos dariam a outras vidas justificativas para se orientarem de outras maneiras numa outra ficção da realidade. Junto à ausência de um sistema instituído, naquela sala de aula de matemática vinha: eles nunca foram à escola! A escola normatizadora traduziria a resposta. A escola é prudente, deixando de lado a fabulação que liga vida e ficção. 
Naquele dia, naquela escola, rasuravam-se modos já tramados em fabulações e produziam-se outras tramas fabuladas fazendo nascer a invenção com desconfiança do estabelecido e normatizado.

Que se fazia na, da e com aquela aula de matemática?

Uma fazeção com a produção de calendários com o viver e com um e muitos calendários e acontecimentos. Na fazeção de e com calendários, algo que "nos dá sinal e nos espera" (DELEUZE, 2000, p.152). Uma proposta - inventem um calendário - inaugurando algo com a produção de calendários que escapa ao ocorrido com essa produção, "um esplendor e um brilho" (DELEUZE, 2000, p.152) produzindo vida com a vida.

\section{Calendário: ou uma torção de julho aliado ao viver}

Fecha-se os olhos para a preeminência fundamental das forças de uma ordem espontânea, agressiva, conquistadora, usurpadora, transformadora e que dão incessantemente novas direções; a adaptação está, de início, submetida à influência delas

(NIETSZCHE, 2009).

Calendário: um único mês: julho. Há necessidade de produzir um mês para um calendário anual que só possuiria esse mês? Essa organização não seria a de um ano, então? Que ano? Que mês? E a caracterização de um calendário como anual não traz um reconhecimento com aquele que utilizamos no cotidiano da vida? Que variações e escapes uma proposta possibilita? Como uma abertura produz um corpo? Reconhece-se um calendário em que os anos são organizados em meses e os meses em dias. Uma aproximação ao estabelecido? Apego? Como desapegar-se do estabelecido? Como escapar ao representado instituído?

A quantidade de dias fazendo-se no único mês em função da quantidade e distribuição dos feriados. Cria-se um modo de operar.

Nem todo dia pode ser feriado!

Há outras ocupações relevantes ao viver. Algumas dessas se dão em feriados, quando a vida ocupa-se com o ócio. Outras, nos dias determinados às funções de manutenção da vida, quando a vida nega o ócio, agora faz negócio. Alguma dose de manutenção da vida insinua-se necessária. Que dose? Como dar conta do quanto dessa dose? Como o ócio pode, também, manter e produzir vida? Como o negar o ócio nega, também, a vida mantendo-a submetida? “Mas o ócio não é a ociosidade, no sentido de tempo vazio. É, pelo contrário, o espaço preenchido pela atividade humana celebrando a pujança da vida, na revelação de sua transcendência aos inevitáveis limites que ela comporta" (LARA, 1998, p. 84). 
Um calendário organizado em um mês de trinta e seis dias e há nove feriados. Um quarto de ócio junto à rotina, configurando-se como uma elaboração com a vida. Há dias estabelecidos como feriados. Um calendário para todos? Ou cada modo de viver inventando seu calendário? Como se dá uma manutenção da vida junto ao viver? Manutenção estabelecida previamente ao vívido? Fazendo negócio? Coercitiva? Arriscando-se no ócio? Facultativa? Manutenção se dá junto aos acontecimentos do vívido, de um modo "[...] singular e por isso coletivo e privado ao mesmo tempo, particular e geral, nem individual nem universal" (DELEUZE, 2000, p. 152)? Inventada junto aos acontecimentos? Manutenção estabelecida? Manutenção provisória? Manutenção como norma?

Rouba-se um nome de um mês de um calendário: julho. $\mathrm{O}$ avesso de um apego a um calendário instituído, fabulando em ficção aliada à vida, rouba-se "ao invés de regular, reconhecer e julgar. Pois reconhecer é o contrário do encontro" (DELEUZE; PARNET, 1997, p. 8). Um roubo produz um desarranjo com uma normatização do tempo. Um acontecimento no roubo. Um mês de julho mais extenso do que o de certo calendário que também possui um mês com esse nome. Ficção de ficção. Fabulação noutra fabulação, tramando entre ócio e negócio.

No julho inventado, cinco semanas completas. Semanas? Algo se mantém em fabulação. Os nomes dados aos dias das semanas também são roubados de um calendário estabelecido previamente à invenção dele, que vai sendo conhecido e reconhecido antes da escola e na escola. Escoa-se por frestas produzidas pelo vento e pela chuva no muro. Roubos como apropriações. "Apropriar-se, apoderar-se, subjugar, dominar são os caracteres da força ativa. Apropriar-se quer dizer impor formas, criar formas explorando-se as circunstâncias" (DELEUZE, 1976, p. 22). Toma-se posse, fabulando com vida aliada à ficção. Um mês sendo inventado, feito seu permite ócio, compondo com negócio. Semanas sendo inventadas, feitas suas. Como inventamos nossas semanas, nossos meses e anos? Como modos de viver são inventados junto ao estabelecido que se esqueceu ser, também, ficção?

Apoderamento de um modo de organizar o tempo cronológico, disparando produção de um modo de viver forte. Um mês seu, um seu provisório junto à produção de mundo (KASTRUP, 1999). Inventar um calendário com o mundo e invenção de um modo de vida fortalecido, fortalecendo-se, com um marcador de tempo estabelecido. Um viver forte "no que acontece" (DELEUZE, 2000, p. 152).

\section{Calendário: ou ensaios com escapes ao estabelecido}


Rio de Janeiro, hoje é vinte e três do três. Como vão as coisas de mês em mês? Eu me sento pra escrever pra você

(LEONI, 2002).

Risco produz insegurança.

Que modos de vida inventam-se

Que modos de vida inventam-se lançados à insegurança? Ao conceber com uma resistência à insegurança? que o estabelecido, que se sustenta em Abrigam-se na verdade única. Produção e submeter o viver, é uma produção, reprodução de normatizações e seus modos constituídos junto a ele são dispositivos de controle que escapam à empoderados, produzindo-se insegurança, abrigando-se no que se pode singularidades. Viver potente e reconhecer. Viver submetido. inventivo.

Noutro canto da sala: outro calendário. Um calendário no qual a quantidade de meses e de dias por mês é o quanto cabe na folha de papel. Nele, um único feriado.

Vinte e três de março. É meu dia!

Apoderar-se do estabelecido: tomando posse de dias, de meses e de suas organizações, inventando outros modos de operar com eles. Tornam-se seus num viver forte.

Outra ordem anual: março, o primeiro mês, seguido de junho, julho, outubro, dezembro e fevereiro. E recomeça um ciclo. Tempo em ciclos?

[...] não mais um círculo do tempo, porém um turbilhão, já não uma ordem do tempo, mas uma variação infinita, nem mesmo uma forma do tempo, mas um tempo informal, plástico. Com isto, estaríamos mais próximos, sem dúvida, de um tempo da alucinação do que de uma consciência do tempo (PELBART, 2004, XXI).

Perder a consciência? Não se dar ciente do tempo demarcado a ser vivido, por viver. Fazer do tempo um vívido. Tecer tempo forte com o que implica. Um turbilhão compondo um emaranhando com meses, uma unidade de medida de tempo cronológico. Esse tempo não estaria, constantemente, em um emaranhado? Como constituir uma vida, concebendo-se que se está constantemente compondo um emaranhado? Emaranhado: instável, misturado, confuso, com-plicado. Implicar-se, mover-se em diversas direções e sentidos, sem uma préocupação com um trajeto, estando ainda no entre. Ocupando-se com o entre. Como organizar uma vida? Uma vida solicita organização? E um viver, como ação, solicita organização?

Concebe-se um calendário composto por seis meses, todos eles com vinte e cinco dias enumerados. Um viver vai sendo produzido com a rotina preestabelecida dos dias da vida. Como o viver se dá com o estabelecido? Operar com o estabelecido ao seu modo, fabricandose um modo. 
Um calendário que se constitui como apropriação e produção de um viver forte e um calendário reconhecido: quantidades padronizadas de dias organizados em meses nomeados da mesma maneira e um dia destacado, como um aniversário, tornado seu. Como uma resistência em nos desprendermos do estabelecido vai sendo produzida? Como produzimos com o estabelecido? Como lidamos com o risco do desprendimento? Roubando dessa organização de tempo cronológico e compondo, nos roubos, emaranhados outros e vívidos.

\section{Calendário: ou invenções provisórias de si}

Seis meses em desordem: fevereiro, janeiro, abril, março, setembro e dezembro. Anuncia-se num dizer outra fabulação, ligando ficção à vida.

É assim que eu sou: desorganizado.

Desordem remete à negação da ordem. A ordem? A desordem? Como apostar nas dezordens? Como tramar com o que vai sendo? Como ruir com o que sou? Fazer falir a ordem e seu negativo, a desordem, fazendo nascer tantas outras ordens quanto possível serem inventadas. Fazer falir a crença na estabilização e na invariância. Falir a crença no eu da ação, pois embora "destituído de existência concreta, a presença do eu não é inócua, ela produz efeitos" (KASTRUP, 1999, p. 158). Apostar no risco da proximidade com o caos da vida, com a imanência do viver inventando vidas outras. Na ausência de crença de uma única ordem e de um eu enquanto substância da vida: perturbação. Perturbar: "afetar, colocar problema" (KASTRUP, 1999, p. 115).

Produzir-se noutra certa ordem cria uma abertura à produção de modos de variação do tempo, fazendo variar vida. Um calendário em invenção, proporcionando a produção de variações, desestabilizando a habitual ordem de um calendário reconhecido e utilizado na rotina da vida. Pensar a rotina e a vida como tantas outras ficções fabuladas permite pensar a si como invenção e ao mundo como invenção que lhe é coengendrada.

\section{Estou inventando outras coisas: não é uma ordem.}

Inventando-se com coisas outras. Um acidente com os quadros riscados no papel? Inventando-se com coisas outras. Em quadros riscados no papel, justapostos e divididos em quatro colunas e seis linhas abriam-se células, fazia-se outro calendário. Cada célula dos quadros, contendo um número de um a vinte e quatro em ordem crescente. Depois da célula enumerada como vinte e três, no quadro denominado abril, uma célula enumerada como vinte e um. Ao lado deste quadro, outro denominado março. Nele, na sequência da célula vinte, uma enumerada vinte e dois. E seguiam enumeradas da vinte e três a vinte e cinco. Uma 
leitura considerando uma separação entre os quadros. Tempo como lineariedade e divisibilidade.

Um mês de abril de vinte e três dias. Ao lado dele, um mês de março contendo vinte e cinco. E uma sexta feira de março acontecendo em abril, dia vinte e um. Outra leitura com um embrenhar-se dos meses, um no outro. Um acidente faz março invadir abril? Um março acontece num abril. "O acontecimento não é o que acontece (acidente), ele é no que acontece" (DELEUZE, 2000, p. 152).

Como inventar-se num tempo outro? Que efeitos certa divisão do tempo produz? Vida com fragmentação e viver que a invade. Um viver é como carro sem freio, como cavalo sem rédeas. Não se podem dominá-los. Viver dá-se em continuidade e em rupturas, em processualidade. Como produzir outros sentidos noutros tempos? Como produzir outros modos noutros tempos? Um modo é um viver, percebido o tempo como duração (KASTRUP, 2005) indivisível, infragmentável, potência, transformação (ROCHA, 2006).

Um mês começa e termina. Um viver começa? Termina? Como processualidade se dá com um calendário? Submete-se um viver à repetição de um começo e de um fim? Como operar com uma organização e uma ordem, ambas prévias, junto ao viver? Previsibilidade comunga com viver? Arriscar-se em dezordens, fazendo-se nascimento de sentidos com o nascimento de si e de mundo: uma aposta.

\section{Calendário: ou uma menina que torce verdades}

Dizem que sou louco por pensar assim (MUTANTES, 1972).

Um calendário reconhecido institucionaliza datas para as singularidades numa leitura universal e totalizante das vidas que constitui. Todas e todos comemoram o Dia das Mães. Todas e todos têm mães? E as e os que têm, comemoram igualmente suas mães? Todas as mães comemoram a maternidade do mesmo modo? Haveria um dia para comemorar as multiplicidades de modos de ser mãe? Aquele calendário faz estável, invariante o ser mãe e atribui-lhe um dia: o segundo domingo do quinto mês de sua lista de doze meses. Em um tempo reservado comemora, põe em destaque, o que muitos dispositivos e seus discursos e seus engendramentos e suas máquinas conseguiram fazer crer na atribuição de formas às forças. Estabilização às resistências e aos movimentos e aos modos e aos desvios. Insistência no geral e universal, apartando ao modo único como o possível: mãe é a que cuida da vida dos filhos e das filhas com seu amor materno. Uma data comemora vidas de mulheres, todas as 
mulheres, que têm mais um desejo: amor materno. "E a não realização desse desejo - por não conseguir ou não querer ser mãe, por não conseguir amar o filho ou a filha ou dar-lhe uma direção satisfatória na vida - pode ser o mote de muitas frustrações. Assumindo o mito, assumimos junto às responsabilidades por ele incitadas" (RITTI, 2015, p. 145). Um mito e sua fabulação ligando ficção e vida? Segue-se comemorando, naquele calendário, as mães.

Convergindo com um modelo, uma menina determina: dezoito de abril - Dia dos Pobres - e dezoito de março - Dia dos Doidos. Institui datas específicas.

\section{Para valorizar alguém que é reprimido na rotina.}

Converge com o modelo em modo. Faz dele problema e escapa, diverge, ensaia um respiro: incomoda-se com o instituído e com o normativo.

Compartimentaliza singularidades? Problematiza multiplicidades. Institui diferenças? Resiste e se movimenta com diferenças. Uma invenção de anormalidades produz uma menina que concebe mundo em viver com multiplicidades. Que se constitui desse modo e constitui um mundo assim. Percebendo discursos prévios, produzindo ilusórios e vulneráveis padrões, arrisca-se e lança-se à contramão desse fluxo. Experimenta produzir respiros frente ao que se constitui como restos ou excessos inapropriados a serem corrigidos e eliminados. Torce e rompe discursos. Produz respiradouros e afirmação de vida, de viver.

\section{Calendário: ou o mínimo de critérios possíveis possibilitando alguma invenção}

Em outro canto da sala, uma criança colore alguns traçados em uma folha de caderno. O primeiro dia, em vermelho, estabelece um feriado.

É que a criança é inocência e esquecimento, um novo começar, um brinquedo, uma roda que gira por si própria, primeiro móbil, afirmação santa. $\mathrm{Na}$ verdade, irmãos, para jogar o jogo dos criadores é preciso ser uma santa afirmação; o espírito quer agora a sua própria vontade; tendo perdido o mundo, conquista o seu próprio mundo (NIETZSCHE, 2011, p. 28).

Não tem do que ser. Vai ser dia do que inventarem a cada ano.

Em outro mês, ao lado, dias representados por 5, 6, 7 e 8. Dia 8 também marcado como feriado indeterminado. Um calendário em invenção e solicitando invenções. Provisoriedade eterna. Solicitando um estar sensível ao momentâneo e presente e, com isso, inventa sentidos e valores.

Sabe-se o que Nietzsche chama de transmutação, transvaloração: não é uma mudança de valores, mas uma mudança no elemento do qual deriva o valor dos valores. A apreciação em lugar da depreciação, a afirmação como vontade de poder, a vontade como vontade afirmativa (DELEUZE, 1976, p. 79). 
Sem institucionalizações que resistam a mais que acontecimentos locais e singulares, uma criança compõe, com uma proposição de uma aula de matemática, uma metodologia: um único critério - escolher dias para serem feriados - possibilitando invenção - feriados sendo inventados local e momentaneamente, no viver. Modo de produção de um calendário: abertura. Inventa um modo que flui em aberturas e potencializa presença e composição. Apodera-se de um modo. Empodera-se ao operar com ele. Um viver solicitando uma política de invenção numa estética atenta a uma vida bela e potente.

Vai ser dia do que inventarem a cada ano.

Dar-se espaço e tempo ao acontecimento. Deixar-se aberto aos arranjos que se fizerem com o viver na implicação com a vida.

\section{Calendário: ou um viver inventando-se}

Um ano composto por três meses: quarenta e três dias, no total. Seis dias do ano para destruir a escola. Um menino de boletim azul. Um nome ausente no livro de advertências escolares.

Dia de destruir a escola.

E você faria o quê, ao destruir a escola? - uma pausa, os olhinhos virados pra cima.

Teria outras coisas no lugar destas. Teria uma piscina e quadras para vários esportes. Aula de música e de dança. Camas e sofás. E várias refeições no dia.

E sala de aula?

Não teria.

E turmas, provas, notas, aprovação?

Não, não.

E aprendizagem?

Ah, isso teria. Um largo sorriso estica as bochechas redondas. E teria professoras também. E mais crianças. E sem relógios. Passaríamos o dia quase todo aqui. E seria tudo diferente.

Formas: uma criança bem-sucedida no sistema escolar. Efeitos de forças: uma criança inventa dias de destruir a escola, seu principal feriado. Dá conta de um modo de lidar com o sistema, abafando-se? Atenta ao funcionamento da maquinaria da escola, inventa outros modos. Produz com o sistema um romper. Destruir o sistema para respirar? Elabora modos de dar conta de solicitações estabelecidas e modos de romper com verdades prévias. Inventar escola. Inventar vacúolos de respiração. Respirar para viver. 
Como lidar com o sistema, junto dele, de modo potente e inventivo? Como respirar junto à maquinaria do sistema, produzindo vacúolos nos sistemas? Como inventar modos de viver esgarçando a vida, escapando com a vida?

Um menino tensiona o sistema e escapa com ele. Não nega a escola, inventa uma escola em que se respire. Variação do e no sistema, levando escola ao seu limite: desconfigura seus dispositivos e métodos e, junto com essa maquinaria, propõe fluxos outros no sistema. Um menino que se recusa a pular os muros e fugir da escola, escapa dela com ela. Produz gagueira (DELEUZE, 2011) no sistema escolar, tensionando-o. Sufoca uma escola sistematizada e compõe com uma escola variante um romper em que se possa respirar.

\section{Invenção de calendários e de desconfianças}

Uma proposta de produção de calendários ensaiando abertura. Evitando estipular mais critério do que um mínimo, intencionando potencializar invenções. Escapando aos direcionamentos excessivos. Produzem-se alguns critérios que atendam a esse mínimo necessário: nomes, dias e feriados.

Fazeção: calendários. Outros critérios vão sendo inventados. Tomar um, dois, seis meses e torná-los outros, produzindo quantidades de dias e datas comemorativas, mudando suas ordenações estabelecidas ou negando uma produção de ordenações.

Uma aula de matemática de uma escola pública baseada em alguns pressupostos: tempo organizado em dias, meses e anos. Escapando a uma reapresentação de um calendário instituído e aos exercícios de fixação e aplicação, propondo pensar processos de invenção com o tempo que constituem modos de vida junto ao viver. Aula de matemática como espaçotempo de produção de modos de viver e de um mundo. Vida e mundo como efeitos de invenção. Propondo-se a um embate com uma representação de uma forma estabelecida, problematizando formas prévias e dadas e efeitos de jogos de forças que fortalecem suas estagnações. Abertura à experiência (LARROSA, 2002) com invenções junto a uma ação de organização e ordenação, nesse caso, do tempo. Como invenção se dá como acontecimento junto a uma ação de produção de um modo de operar com o tempo? Há acontecimento aquilo no que acontece - na organização do tempo? Se organizado o tempo, acontecimento há? Organizar o tempo coopera com a manutenção da vida e das formas normatizadas de viver? Tornar tempo problema produz efeitos na invenção de vida e de mundos? Que efeitos vão sendo produzidos com problematizações dessa ação? 
Aulas de matemática sobre unidades de medida de tempo. Quanto é necessário dar conta do sistema? Como dar conta do sistema? Que modos de vida são produzidos com o sistema? Como produzir um viver potente sem negar uma sistematização a favor da manutenção da vida?

\section{Normais não! Estes calendários não são iguais ao nosso.}

Invenção acontecendo na sala de aula de matemática, junto ao estabelecido, produzindo modos de viver e pensar. Meses com quatro, quarenta e um, doze, vinte, dois mil e quatorze dias. Dias de doze horas. Anos de um, dois, quatro meses. Meses com e sem uma organização em semanas. Junto a uma organização estabelecida: horas em dias, dias em meses, meses em anos - se dão invenções de calendários e de modos de viver. Junto à produção de calendários, vão sendo inventados problemas com o normativo e com a produção de sentidos. Dando-se acontecimentos. Com problematizações com o instituído e invenção de modos de operar com o tempo, vão sendo produzidos apoderamentos junto ao tempo cronológico e empoderamentos com a invenção de modos de operar com ele, de modos de viver junto ao cronológico, de inventá-lo como seu. De insistências e resistências a modelos prévios. De ação junto à vida. De invenção do viver. De um viver potente.

Uma aula de matemática decompondo verdades e certezas tatuadas por discursos e práticas apresentados e representados por um modo de vida. Disparando pensar no pensamento. Uma aula de matemática apostando no poder fabulador da ficção e de sua potência falseadora de mundos. Fabulando e criando mundos e produzindo vidas.

Aula de matemática possibilitando encontros com: Como assim, normal? Como assim normal ter o mesmo sentido de igual ao nosso? Como assim normal não ter o mesmo sentido de igual ao nosso? O que não reconheço em meu modo de vida não é normal? Que normal? Como a invenção de uma normalidade produz efeitos como modos de viver? Normalidade, normatividade, padronização. Escapes. Abafamentos. Respiradouros. Viver.

A fazeção, por vezes, compunha-se em decompor certo calendário. Decompor como apodrecimento que deteriora a matéria produzindo vida. $\mathrm{E}$ algumas marcas disparando outros modos de operar com o tempo cronológico. Escapando ao estabelecido sem negação: fugindo à vida com a vida. Que isso implica?

Estar no limite do abismo, no mais limiar. Saltar? Um salto produziria morte? Quanto de morte produz nascimento de vidas outras? Fazer nascer dias sem datas preestabelecidas a serem comemoradas. Fazer nascer um dia só seu. Fazer nascer dia daqueles que estão à margem de serem comemorados. Fazer nascer dias de destruir um estilo de escola que abafa e submete. Fazer nascer... 
Cada um inventando seu calendário: apoderamento de um modo de operar com o tempo cronológico, empoderamento de um modo de viver. Produção de uma aposta: inventando seu calendário torna-se mais potente inventar práticas e pensar junto ao instituído, também uma produção, sem submeter-se a ele. Fazer um exercício com ficção, opondo-se ao modelo de verdade. Encontrar o elo entre vida e ficção: fabulando, inventando. Criando mundos, produzindo-se, numa aula de matemática.

Efeitos com uma aula: estremecimento de verdades impostas, de normas instituídas. Respiradouro para modos de viver que escapam à normalidade. Aula como disparador da invenção de modos de viver que não se enquadram, que esgarçam a realidade produzindo outras tantas.

Efeito de instituir o que escapa a certa normalidade? Efeito de pôr em movimento o que se instituiu, provisoriamente, como certa normalidade? Pensar como provisoriedade uma produção de sentidos e de valores. Uma aula de matemática como ensaios com o viver. Esburacando certos sistemas e suas maquinarias.

\section{Referências}

CLARETO, S. M.; ROTONDO, M. A. Sacramento. Como seria um mundo sem Matemática? Hein?! Na tensão narrativa-verdade. Bolema: Boletim de Educação Matemática, Rio Claro, v. 28, n. 49, p. 974-989, 2014.

DELEUZE, G. Crítica e clínica. Tradução de Peter Pál Pelbart. 2. ed. São Paulo: Editora 34, 2011. $208 \mathrm{p}$.

Lógica do sentido. 4. ed. São Paulo: Perspectiva S.A., 2000. 341 p.

Nietzsche e a filosofia. Tradução de Ruth Joffily Dias e Edmundo Fernandes Dias. 1. ed. Rio de Janeiro: Editora Rio, 1976. 90 p. $166 \mathrm{p}$.

; PARNET, C. Diálogos. Tradução de Eloísa Araújo Ribeiro. 3. ed. São Paulo: Escuta, 1997.

FOUCAULT, M. Os anormais: curso no Collège de France (1974/1975). Tradução Eduardo Brandão. 1. ed. São Paulo: Martins Fontes, 2001. 479 p.

KASTRUP, V. Políticas cognitivas na formação do professor e o problema do devir-mestre. Disponível em: <http://www.scielo.br/pdf/es/v26n93/27279.pdf>. Acesso em 12 ago. 2005.

. A Invenção de si e do Mundo: uma introdução do tempo e do coletivo no estudo da cognição. 1. ed. Campinas: Papirus, 1999. 216 p.

LARA, T. A. A escola que não tive... o professor que não fui: temas de filosofia da educação. 2. ed. São Paulo: Cortez, 1998. 248 p.

LARROSA, J. Notas sobre a experiência e o saber de experiência. 2002. Disponível em: <http://www.scielo.br/pdf/rbedu/n19/n19a02.pdf >. Acesso em: 12 ago. 2002. 
LEONI. As cartas que eu não mando. (música) Rio de Janeiro: EMI Brasil, 2002. 1 CD.

MUTANTES, Os. Balada do louco. (música). De Arnaldo Baptista e Rita Lee. Gravação no álbum Mutantes e Seus Cometas no País dos Baurets, 1972. 1 CD.

NIETZSCHE, F. Assim falou Zaratustra: um livro para todos e para ninguém. 6. ed. São Paulo: Companhia das Letras, 2011. 360p.

PELBART, P. O Tempo Não-Reconciliado: Imagens do Tempo em Deleuze. 1. ed. São Paulo: Perspectiva, 2004. 192 p.

PIMENTEL, M. R. Fabulação: a memória do futuro. 2010. 152 f. Tese (Doutorado em Letras) Programa de Pós-graduação em Letras, Pontifícia Universidade Católica do Rio de Janeiro (PUC-RJ), Rio de Janeiro, 2010.

RITTI, R. C. de O. “A gente cria todo dia! A gente cria a vida!”: pesquisar com mulheres mães na periferia. 2015. 285 f. Tese (Doutorado em Educação) - Programa de Pós-Graduaçao em Educação, Universidade Federal de Juiz de Fora (UFJF-MG), Juiz de Fora, 2015.

ROCHA, S. P. V. Tornar-se quem se é: educação como formação, educação como transformação. In: FEITOSA, C.; BARRENECHEA, M. A.; PINHEIRO, P. (Org.). Nietzsche e os gregos: arte, memória e educação. Assim falou Nietzsche V. Rio de Janeiro: Ed. DP\&A, 2006. p. 267-278.

TEATRO MÁGICO, O. De ontem em diante. (poesia/música). De Fernando Anitelli. Gravação independente, 2003. $1 \mathrm{CD}$.

Submetido em Junho de 2016. Aprovado em Outubro de 2016. 